\title{
Denosumab as the Treatment of Recalcitrant Tuberculous Pleural Effusion-Associated Hypercalcemia
}

\author{
Afdhal Afiq Abd Jalil, ${ }^{1}$ Sharifah Faradila Wan Muhamad Hatta $\mathbb{D}^{1,2}$ \\ Aimi Fadilah Mohamad $\mathbb{D D}^{1,2}$ and Mohammed Fauzi Abdul Rani ${ }^{1}$ \\ ${ }^{1}$ Department of Internal Medicine, Faculty of Medicine, Universiti Teknologi MARA, Sungai Buloh, Selangor, Malaysia \\ ${ }^{2}$ Endocrine and Diabetes Unit, Department of Internal Medicine, Faculty of Medicine, Universiti Teknologi MARA, Sungai Buloh, \\ Selangor, Malaysia
}

Correspondence should be addressed to Sharifah Faradila Wan Muhamad Hatta; shfara@gmail.com

Received 8 February 2021; Revised 22 March 2021; Accepted 13 April 2021; Published 20 April 2021

Academic Editor: Bruno Megarbane

Copyright (C) 2021 Afdhal Afiq Abd Jalil et al. This is an open access article distributed under the Creative Commons Attribution License, which permits unrestricted use, distribution, and reproduction in any medium, provided the original work is properly cited.

\begin{abstract}
Denosumab is a human monoclonal antibody that binds to RANKL (receptor activator of nuclear factor-kappa B ligand). It has mainly been used in the treatment of osteoporosis for a variety of causes especially in situations refractory to bisphosphonates or when kidney function is impaired. It is also used in cases of malignancy-associated hypercalcemia. There are many causes of hypercalcemia, but only rarely it is associated with granulomatous diseases such as tuberculous pleural effusion. We report a case of hypercalcemia from tuberculous pleural effusion that was initially admitted with left medium abundance pleural effusion and a serum corrected calcium level of $3.48 \mathrm{mmol} / \mathrm{L}$. The calcium level was successfully normalized within 72 hours of subcutaneous denosumab administration after other interventions have failed.
\end{abstract}

\section{Introduction}

Hypercalcemia has often been described in patients with granulomatous disorders, but they are rarely symptomatic [1-4]. Among them, pulmonary tuberculosis is the most common cause but less so among extrapulmonary cases. Locally, the incidence has been reported to be around $27.5 \%$ among patients with active tuberculosis [4], which is comparable to the incidence rate in the west or a high $\mathrm{TB}$ incidence country such as India $[5,6]$.

Acute treatment of hypercalcemia from any cause includes intravenous volume repletion or hydration, coupled with bisphosphonate, calcitonin, or denosumab, if the hypercalcemia persists despite hydration. The most suitable choice of treatment depends on the patient's clinical condition, which includes renal function status.

Denosumab is a human monoclonal antibody that inhibits the formation, function, and survival of osteoclasts and reduces bone resorption. It has been used for the treatment of hypercalcemia as an alternative to bisphosphonate, especially in patients with reduced creatinine clearance $[7,8]$.

We report a case of hypercalcemia secondary to extrapulmonary tuberculosis successfully treated with denosumab after other interventions have failed to reduce the calcium level.

\section{Case}

A 70 -year-old male with a known history of type 2 diabetes mellitus, hypertension, chronic kidney disease, and ischemic heart disease presented to the emergency department with 7day history of gradual onset of shortness of breath, reduced effort tolerance, and lethargy. On further inquiry, there was loss of appetite for a month, but he denied any accompanying weight loss, and there was also no history of fever or night sweats. He admitted to vague abdominal and back pain that lasted for a week.

At the emergency department, he looked cachexic and dehydrated but was alert to time, place, and person. He was 
apyrexial with a pulse rate of 88 beats per minute and blood pressure of $131 / 72 \mathrm{mmHg}$, but tachypnoeic with a respiratory rate of 27 breaths per minute. The oxygen saturation, however, was maintained at $98 \%$ on room air. Respiratory examination revealed left-sided stony dullness up to the midzone on percussion with reduced air entry on the same side. Cardiovascular and gastrointestinal examinations were unremarkable.

Chest radiograph confirmed the presence of a left medium abundance pleural effusion (Figure 1).

Table 1 summarizes the results of the blood investigations including hypercalcemia with a level of $3.03 \mathrm{mmol} / \mathrm{L}$.

He was initially admitted to the ward for treatment with intravenous Augmentin and $0.9 \%$ saline hydration for presumed acute-on-chronic kidney injury as we did not have any baseline kidney function, but unfortunately his breathing deteriorated rapidly a day after admission. He became more tachypnoeic, and the arterial blood gases showed type 2 respiratory failure $\left(\mathrm{pH}, 7.32 ; \mathrm{pO}_{2}, 62 \mathrm{mmHg}\right.$; pCO2, $50 \mathrm{mmHg} ; \mathrm{HCO}_{3}, 20$; lactate, 3). In view of the worsening ventilation and his general medical condition, a decision was made to invasively ventilate him in the intensive care unit (ICU). In the ICU, his antibiotic was upgraded to intravenous piperacillin/tazobactam for presumed community-acquired pneumonia with pleural effusion and intravenous $0.9 \%$ saline $1000 \mathrm{mls}$ over 24 hours for hydration was maintained.

Echocardiography demonstrated globally dilated severe hyperkinesia of the left ventricle and a severely impaired systolic function with a left ventricle ejection fraction of $20 \%$. Because of this, the fluid balance was closely monitored to minimize the risk of pulmonary congestion.

His urine output remained good with an average of $100 \mathrm{mls} / \mathrm{h}$ equivalent to $1.4 \mathrm{mls} / \mathrm{kg} / \mathrm{h}$. Unfortunately, despite adequate hydration and a positive balance of $900 \mathrm{mls}$ averaging over 3 days, his serum calcium continued to rise to $3.48 \mathrm{mmol} / \mathrm{L}$.

Intravenous furosemide was also initiated as a forced diuresis measure, which also failed to bring the calcium down.

Further investigations for the cause of the pleural effusion included therapeutic and diagnostic left thoracocentesis, and blood tests for the cause of hypercalcemia were conducted during admission. The results are listed in Table 2.

To reduce the calcium, we decided to try him on subcutaneous denosumab at the dose of $120 \mathrm{mg}$, and his serum corrected calcium gradually improved to $2.40 \mathrm{mmol} / \mathrm{L}$, as depicted in Table 3, after 4 days with no further drop in calcium thereafter.

At day 5, the pleural fluid analysis for rapid mycobacterium liquid culture and sensitivity test came back positive for Mycobacterium tuberculosis complex. The treatment for tuberculous pleural effusion with isoniazid, rifampicin, pyrazinamide, ethambutol, and pyridoxine (2HRZ/4HR) was subsequently commenced.

He was successfully extubated after 10 days in the ICU and was transferred to the general medical ward for further management. Unfortunately, he developed a severe

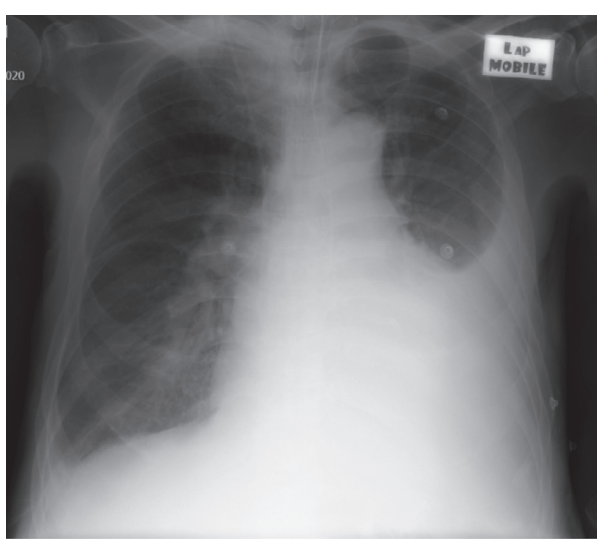

FIgURE 1: Left medium abundance pleural effusion.

concomitant hospital-acquired pneumonia complicated by respiratory failure that eventually led to multiorgan failure, cardiorespiratory arrest, and death.

\section{Discussion}

Hypercalcemia can rarely be a manifestation of granulomatous disease including pulmonary tuberculosis [3], even rarer in tuberculous pleural effusion as in our case.

Evaluation of hypercalcemia in our patient was suggestive of a parathyroid-independent mechanism of hypercalcemia with elevated level of vitamin D. In normal situations, vitamin $\mathrm{D}_{3}$ is absorbed by the skin from ultraviolet $\mathrm{B}$ light which is then metabolised into $25(\mathrm{OH}) \mathrm{D}_{3}$ in the liver by 25 -hydroxylase. $25(\mathrm{OH}) \mathrm{D}_{3}$ is then catalysed via $1-\alpha$-hydroxylase to an active form known as 1,25-dihydroxyvitamin $\mathrm{D}_{3}\left(1,25(\mathrm{OH})_{2} \mathrm{D}_{3}\right)$ which aids in calcium absorption in the gut [9].

Tuberculosis patients experience dysregulated extrarenal production of $1,25(\mathrm{OH})_{2} \mathrm{D}_{3}$ by activated alveolar macrophages which leads to increased calcium absorption in the gut and thus hypercalcemia [10]. Overproduction of $1,25(\mathrm{OH})_{2} \mathrm{D}_{3}$ is a protective mechanism against oxidative injuries due to the nitric oxide burst from granulomatous macrophages [11]. Unfortunately, in some individuals, this protective mechanism has led to a different complication. However, not everyone who suffers from TB would develop hypercalcemia as $1,25(\mathrm{OH})_{2} \mathrm{D}_{3}$ is usually produced in small quantities locally and is not brought to target sites for the regulation of calcium homeostasis. This mechanism has been associated with hypercalcemia in pulmonary TB; however, the underlying cause for hypercalcemia in tuberculous pleural effusion, as seen in our patient, remains uncertain.

A theory has been proposed that hypercalcemia in tuberculous pleural effusion could be secondary to circulating monocytes, which act as a source of 1- $\alpha$-hydroxylase that could convert $25(\mathrm{OH}) \mathrm{D}_{3}$ to $1,25(\mathrm{OH})_{2} \mathrm{D}_{3}$. This $1,25(\mathrm{OH})_{2} \mathrm{D}_{3}$ produced by monocytes acts locally and when carried to target tissues, it may play a role in calcium homeostasis, unlike alveolar immune cells which only acts locally [12].

The management of hypercalcemia depends on the level of serum calcium, clinical symptoms, and the underlying disorder. The treatment would always start with adequate hydration and forced diuresis with furosemide followed by 
TABLE 1: Baseline blood investigation.

\begin{tabular}{lcc}
\hline Investigation & Results & Normal values \\
\hline Haemoglobin & $9.3 \mathrm{~g} / \mathrm{dL}$ & $13-17$ \\
Total white count & $2.48 \times 109 / \mathrm{L}$ & $4-10$ \\
Platelet & $167 \times 109 / \mathrm{L}$ & $150-410$ \\
Sodium & $134 \mathrm{mmol} / \mathrm{L}$ & $135-145$ \\
Potassium & $4 \mathrm{mmol} / \mathrm{L}$ & $3.5-5.1$ \\
Urea & $14.10 \mathrm{mmol} / \mathrm{L}$ & $2.78-8.07$ \\
Creatinine & $212 \mu \mathrm{mol} / \mathrm{L}$ & $62-106$ \\
eGFR & $26.9 \mathrm{~mL} / \mathrm{min} / 1.73 \mathrm{~m}^{2}$ & $>60 \mathrm{~mL} / \mathrm{min}^{2} / 1.73 \mathrm{~m}{ }^{2}$ \\
Magnesium & $1.02 \mathrm{mmol} / \mathrm{L}$ & $0.66-0.99$ \\
Corrected calcium & $3.03 \mathrm{mmol} / \mathrm{L}$ & $2.20-2.55$ \\
Phosphate & $1.33 \mathrm{mmol} / \mathrm{L}$ & $0.80-1.45$ \\
Total protein & $83.9 \mathrm{~g} / \mathrm{L}$ & $64.0-83.0$ \\
Albumin & $30 \mathrm{~g} / \mathrm{L}$ & $35-52$ \\
Total bilirubin & $20 \mu \mathrm{mol} / \mathrm{L}$ & $<21$ \\
Alanine transaminase & $8 \mathrm{U} / \mathrm{L}$ & $<41$ \\
Alkaline phosphate & $146 \mathrm{U} / \mathrm{L}$ & $40-130$ \\
Gamma-glutamyl transferase (GGT) & $67 \mathrm{U} / \mathrm{L}$ & $<60$ \\
Erythrocyte sedimentation rate (ESR) & $>120$ & $1-15$ \\
Full blood picture & Macrocytic anemia: macrocytosis of RBC with polychromatic cells and \\
& & \\
\end{tabular}

TABLE 2: Further blood samples sent for investigation of hypercalcemia.

\begin{tabular}{lcc}
\hline Investigations & Results & Normal values \\
\hline Intact parathyroid hormone & $<0.5 \mathrm{pmol} / \mathrm{L}$ & $1.96-8.49$ \\
Total vitamin D/25-hydroxyvitamin D & $106.30 \mathrm{nmol} / \mathrm{L}$ & $50-125$ \\
Alpha fetoprotein (AFP) & $<1.00 \mathrm{ng} / \mathrm{mL}$ & $0.89-8.78$ \\
CEA & $1.37 \mathrm{ng} / \mathrm{mL}$ & $0.00-5.00$ \\
Prostate-specific antigen & $0.163 \mathrm{ng} / \mathrm{mL}$ & $0.00-4.0$ \\
Immunoglobulin A (IgA) & $4.3 \mathrm{~g} / \mathrm{L}$ & $0.70-4.00$ \\
Immunoglobulin G (IgG) & $26.3 \mathrm{~g} / \mathrm{L}$ & $7.0-16.0$ \\
Immunoglobulin M (IgM) & $1.58 \mathrm{~g} / \mathrm{L}$ & $0.40-2.30$ \\
Kappa free light chain & $352.0 \mathrm{mg} / \mathrm{L}$ & $6.7-22.4$ \\
Lambda free light chain & $493.0 \mathrm{mg} / \mathrm{L}$ & $8.3-27.0$ \\
Kappa/lambda ratio & 0.71 & $0.31-1.56$ \\
Serum protein electrophoresis & No paraprotein band & \\
Urine protein electrophoresis & No paraprotein band & Colour \\
Pleural fluid analysis & LDH (pleural fluid/serum) & Exudative \\
& & 0.75 \\
& Total protein (pleural fluid/serum) & 0.7 \\
\hline
\end{tabular}

TABle 3: Serum calcium level after administration of subcutaneous denosumab.

\begin{tabular}{lcccccccc}
\hline Day (postdenosumab) & 1 & 2 & 3 & 4 & 5 & 6 & 7 & 8 \\
\hline Corrected calcium level $(\mathrm{mmol} / \mathrm{L})$ & 3.44 & 3.43 & 3.28 & 2.46 & 2.97 & 2.40 & 2.52 & 2.43 \\
Serum creatinine level $(\mu \mathrm{mol} / \mathrm{L})$ & 353 & 360 & 370 & 273 & 332 & 234 & 345 & 431 \\
\hline
\end{tabular}

bisphosphonates if both measures have failed [13]. Haemodialysis may be required in the event of renal failure and corticosteroids in patients with sarcoidosis or certain neoplasms [14].

In our patient, bisphosphonate was not chosen as the first-line treatment because of the persistently low creatinine clearance $(\mathrm{CrCl})$ of $<30 \mathrm{mls} / \mathrm{min}$ with a serum creatinine of $212 \mu \mathrm{mol} / \mathrm{L}$ and the worry of further deterioration in renal function. Palmer et al. showed that a quarter of patients with baseline renal dysfunction experienced all-grade serum creatinine elevation when the hypercalcemia was treated with intravenous bisphosphonates. The incidence of serum creatinine elevation was statistically higher in those with a $\mathrm{CrCl}$ of $<30 \mathrm{~mL} / \mathrm{min}$ compared to those with $\mathrm{CrCl} \geq 30 \mathrm{~mL} /$ min [15]. Calcitonin was also not available at our hospital, hence the decision to use denosumab. 
Denosumab is a novel, fully human monoclonal antibody which prevents the receptor activator of nuclear factorkappa B ligand from binding to its receptor and inhibits osteoclast development, activation, and survival. It has no dose adjustments for renal impairment and has a lower incidence of renal failure and acute phase reactions. It has been approved for the treatment of osteoporosis in postmenopausal women and prevention of skeletal-related events including fractures, spinal cord compression, bone pain requiring surgery/radiation therapy, and hypercalcemia in malignancy [16].

To the best of our knowledge, our case report is the second to report improvement in hypercalcemia secondary to tuberculosis with denosumab. The first case by TorresOrtiz et al. reported normalization of serum calcium level at 48 hours postadministration and as the patient survived, they were able to observe hypocalcemia at day 16 postadministration of denosumab [17] which is a known side effect of the drug [18]. When compared with zoledronic acid treatment for patients with advanced cancer with bone metastases or myeloma, $5.7 \%$ of patients who received denosumab required intravenous calcium infusion compared to $2.7 \%$ in the zoledronic acid arm [19]. We were not able to determine if this side effect had occurred in our patient.

During our investigation, ionized calcium could have been done to confirm true hypercalcemia but the presence of two samples of elevated serum total calcium was used instead to indicate true hypercalcemia in our patient.

In conclusion, denosumab is an option for the treatment of refractory hypercalcemia in the setting of low creatinine clearance; however, careful monitoring of calcium levels post-therapy is essential after administration especially in those deficient in vitamin $\mathrm{D}$.

\section{Data Availability}

The clinical data used to support the findings of this study are included within the article.

\section{Conflicts of Interest}

All authors declare no conflicts of interest.

\section{References}

[1] S. Thosani and M. I. Hu, "Denosumab: a new agent in the management of hypercalcemia of malignancy," Future Oncology, vol. 11, no. 21, pp. 2865-2871, 2015.

[2] M. J. Kavanaugh, M. F. Bavaro, R. V. Barthel, R. C. Maves, and H. L. Groff, "Severe hypercalcemia as the presenting sign of tuberculosis," Journal of Medical Cases, vol. 6, no. 8, pp. 382-384, 2015.

[3] A. Rajendra, A. Mishra, N. Francis, and R. B. Carey, "Severe hypercalcemia in a patient with pulmonary tuberculosis," Journal of Family Medicine and Primary Care, vol. 5, no. 2, p. 509, 2016.

[4] C. K. Liam, K. H. Lim, P. Srinivas, and P. J. Poi, "Hypercalcaemia in patients with newly diagnosed tuberculosis in Malaysia," The International Journal of Tuberculosis and Lung Disease: The Official Journal of the International Union Against
Tuberculosis and Lung Disease, vol. 2, no. 10, pp. 818-823, 1998.

[5] A. A. Abbasi, "Hypercalcemia in active pulmonary tuberculosis," Annals of Internal Medicine, vol. 90, no. 3, pp. 324-328, 1979.

[6] T. Y. Chan, C. H. Chan, and C. C. Shek, "The prevalence of hypercalcaemia in pulmonary and miliary tuberculosis-a longitudinal study," Singapore Medical Journal, vol. 35, no. 6, pp. 613-615, 1994.

[7] M. I. Hu, I. G. Glezerman, S. Leboulleux et al., "Denosumab for treatment of hypercalcemia of malignancy," The Journal of Clinical Endocrinology \& Metabolism, vol. 99, no. 9, pp. 3144-3152, 2014.

[8] A. C. Dalkin and M. H. Rosner, "Denosumab in the treatment of hypercalcemia secondary to malignancy," Orphan Drugs: Research and Reviews, vol. 5, pp. 113-121, 2015.

[9] P. J. Tebben, R. J. Singh, and R. Kumar, "Vitamin D-mediated hypercalcemia: mechanisms, diagnosis, and treatment," Endocrine Reviews, vol. 37, no. 5, pp. 521-547, 2016.

[10] J. Cadranel, M. Garabedian, B. Milleron, H. Guillozo, G. Akoun, and A. J. Hance, "1,25(OH)2D2 production by T lymphocytes and alveolar macrophages recovered by lavage from normocalcemic patients with tuberculosis," Journal of Clinical Investigation, vol. 85, no. 5, pp. 1588-1593, 1990.

[11] J.-M. Chang, M.-C. Kuo, H.-T. Kuo et al., "1- $\alpha, 25-D i h y d r o x-$ yvitamin D3 regulates inducible nitric oxide synthase messenger RNA expression and nitric oxide release in macrophage-like RAW 264.7 cells," Journal of Laboratory and Clinical Medicine, vol. 143, no. 1, pp. 14-22, 2004.

[12] R. Parkash, S. Dabla, N. Saini, and K. Bala, "Hyperuricaemia, hypoparathyroidism and acute hypercalcaemia: unusual complications in extrapulmonary tuberculosis," Journal of Clinical \& Diagnostic Research, vol. 13, no. 9, 2019.

[13] M. Waller, S. Murphy, N. Krishnaraj, and G. Antunes, "Respiratory failure and symptomatic hypercalcaemia complicating pulmonary tuberculosis," Case Reports, Article ID bcr1020081081, 2009.

[14] R. Bartl and C. Bartl, "The patient with "hypercalcaemia," Bone Disorders, Springer, Cham, Switzerland, pp. 341-343, 2017.

[15] S. Palmer, F. Tillman, P. Sharma et al., "Safety of intravenous bisphosphonates for the treatment of hypercalcemia in patients with preexisting renal dysfunction," Annals of Pharmacotherapy, vol. 55, no. 3, pp. 303-310, 2020.

[16] E. Tsourdi, T. D. Rachner, M. Rauner, C. Hamann, and L. C. Hofbauer, "Denosumab for bone diseases: translating bone biology into targeted therapy," European Journal of Endocrinology, vol. 165, no. 6, pp. 833-840, 2011.

[17] A. Torres-Ortiz, P. Acharya, and W. Cheungpasitporn, "Successful treatment of tuberculosis-associated hypercacemia with denosumab in a patient with acute kidney injury," Therapeutic Apheresis and Dialysis, vol. 23, no. 5, pp. 484-485, 2019.

[18] B. B. McCormick, J. Davis, and K. D. Burns, "Severe hypocalcemia following denosumab injection in a hemodialysis patient," American Journal of Kidney Diseases, vol. 60, no. 4, pp. 626-628, 2012.

[19] S. A. Boikos and H.-J. Hammers, "Denosumab for the treatment of bisphosphonate-refractory hypercalcemia," Journal of Clinical Oncology, vol. 30, no. 29, p. e299, 2012. 